\title{
Distribution and densities of the decapod crab Percnon gibbesi, an invasive Grapsidae, in western Mediterranean waters
}

\author{
S. Deudero ${ }^{1, *}$, A. Frau ${ }^{1}$, M. Cerda ${ }^{1}$, H. Hampel ${ }^{2}$ \\ ${ }^{1}$ Grup d'Oceanografia Interdisciplinar (GOI)-Institut Mediterrani d'Estudis Avançats-CSIC/UIB, Guillem Colom, \\ Campus Universitari, Ctra. de Valldemossa, km 7.5, 07122 Palma de Mallorca, Spain \\ ${ }^{2}$ Royal Belgian Institute of Natural Sciences, Vautierstraat 27, 1000 Brussels, Belgium
}

\begin{abstract}
Density, population structure and spatial distribution of the invasive crab Percnon gibbesi in western Mediterranean waters were investigated. Densities appeared highest within pebble substrates, reaching up to 3 ind. $\mathrm{m}^{-2}$. Modal length was $20 \mathrm{~mm}$ carapace length (CL), with the presence of ovigerous females from $18 \mathrm{~mm}$ CL. Maximum densities were observed at $1 \mathrm{~m}$ depth. There were significant differences in habitat preference toward boulders of variable size with algal cover not higher than $0.5 \mathrm{~cm}$. Although individuals were highly active during the daytime, activity patterns were highest at sunset. Further studies are required on the biology and ecology of this grapsid crab to better understand the reasons for its population growth along Mediterranean coasts and to ascertain the means of colonization.
\end{abstract}

KEY WORDS: Percnon gibbesi · Grapsidae $\cdot$ Mediterranean · Alien species

\section{INTRODUCTION}

Over the last 2 centuries, an increased number of factors, mediated by human activities, have multiplied the rate at which exotic species are introduced (Simberloff 2001). Researchers have closely watched the phenomenon of invading marine species and their impact on indigenous fauna (Carlton 1989, Carlton \& Geller 1993). Invasive species often represent a potential risk to indigenous biota because they belong to ecosystems with different biotic and abiotic characteristics. In this sense, exotic species can be highly competitive because they name different life strategies that may result in a highly aggressive new population. In many cases, introduced species have the potential to radically alter the structure and function of native ecosystems, causing a decrease in biodiversity (Cercherelli 2002).

In the Mediterranean Sea, among the 11 non-native decapod crustaceans which are present (Briand 2002), one of the last species to have been introduced is the crab Percnon gibbesi (Decapoda, Grapsidae), a small crab with a subtropical distribution. In America, it is distributed from Chile to California and from Florida to Brazil. In Africa, this species can be found from the Gulf of Guinea to the Azores (Galil et al. 2002). P. gibbesi found in Mediterranean waters have the same morphological features as the Atlantic specimens, which suggests that they originated from the Atlantic population and entered the Mediterranean through the Strait of Gibraltar (Pipitone et al. 2001).

More recently, Percnon gibbesi has extended its distribution area within the Mediterranean Sea (Garcia \& Reviriego 2000, Relini et al. 2000, Müller 2001). The first Mediterranean observations of $P$. gibbesi occurred in Isla Linosa, Italy, in 1999 (Relini et al. 2000), and subsequent observations were made in 1999 in the south of Sicily (Mori \& Vacchi 2002), in Pantelleria (Strait of Sicily) and off the coast of mainland Sicily, where both juveniles and ovigerous females were seen (Pipitone et al. 2001). P. gibbesi were also reported in the south of Italy, as well as in Sardinia and Malta 
(Briand 2002). In the Balearic Islands, the first observations were made in 1999 in Mallorca and Minorca (Garcia \& Reviriego 2000), and in Ibiza (Müller 2001), where this species had already established stable populations. The geographical expansion of this species reported from personal observations in Mediterranean waters ranges from the eastern part of the Iberian Peninsula (Barcelona, Columbretes), Balearic Archipelago, Sardinia, Tyrrhenian Sea (Ischia and Ponza Islands) and Sicily to Malta. This wide distribution may reflect the general characteristics of invasive species, namely a high abundance in their native range, a broad diet, short generation times and the ability to survive in a wide range of physical conditions (Ehrlich 1989).

While some studies report the presence of Percnon gibbesi in the Mediterranean (Garcia \& Reviriego 2000, Relini et al. 2000, Müller 2001, Pipitone et al. 2001, Mori \& Vacchi 2002), to our knowledge, no research has quantified the population, density or spatial distribution of this exotic species throughout the Mediterranean. The aims of the present study are therefore to (1) quantify the natural abundance and population structure of the non-indigenous crab $P$. gibbesi in the waters of the western Mediterranean, and (2) examine the distribution of $P$. gibbesi with respect to depth and habitat requirements.

\section{MATERIALS AND METHODS}

Specimens of Percnon gibbesi were counted near the islands of Dragonera and Es Pantaleu, southwest of Mallorca, in the western Mediterranean (Fig. 1). Sampling surveys were carried out from 09:00 to 14:00 h GMT from 23 July to 1 August 2003. Temperature and conductivity of the first $40 \mathrm{~m}$ depth were registered for thermocline delimitation.

Underwater visual census counts were carried out by SCUBA divers and snorklers in transects $50 \mathrm{~m}$ long and $4 \mathrm{~m}$ wide by setting a metric tape along the shoreline at $2 \mathrm{~m}$ depth. Each transect was sampled simultaneously by 2 observers; the first diver was snorkeling and surveyed the area from the mean water level to $2 \mathrm{~m}$ depth; the second diver was equipped with SCUBA equipment and surveyed the crab population from 2 to $4 \mathrm{~m}$ depth. To test for spatial variation, a total of 9 sampling sites were randomly established along the perimeter of the islands (Fig. 1). At each sampling site, 9 transects were set, providing a total of 81 transects. Along each transect, the crabs were counted and their length visually estimated. Records were made of the number of individuals, their carapace lengths, and depth and meter on the metric tape for each observed crab. Each transect was classified into 3 categories for the study of habitat preference: (1) boulders of variable size with algal cover not higher than $0.5 \mathrm{~cm}_{i}(2)$ communities of algal turf and algal sheets higher than $0.5 \mathrm{~cm}$, with dominance of macroalgae such as Cystoseira mediterranea, Dyctiopteris sp., Corallina sp., Acetabularia acetabulum and Padina pavonica; and (3) vertical walls. Data on accompanying crab species, type of community and feeding behavior of Percnon gibbesi were also visually registered at each transect. Variations in density (ind. $\mathrm{m}^{-2}$ ) among the habitat type were tested by 1 -way analysis of variance (ANOVA).

Length-frequency distributions, sex ratio and reproductive output of Percnon gibbesi were calculated from 100 individuals caught by hand; 50 from Dragonera Island and 50 from Sa Ràpita (a site southeast of Mallorca, approx. 45 nautical miles from Dragonera). Length-frequency distributions of $P$. gibbesi populations at Dragonera and Sa Ràpita were compared with a non-parametric Kruskal-Wallis test.

The distribution pattern of Percnon gibbesi was investigated using a 3-way ANOVA. The factors involved in the analysis were: habitat type (3 levels), size of the individuals (6 levels: $<10,10-15,16-20,21-25$, $26-30$ and $>30 \mathrm{~mm}$ ), depth (4 levels: $0-1,1-2,2-3$ and 3-4 $\mathrm{m}$ ). The density (ind. $\mathrm{m}^{-2}$ ) was estimated at each
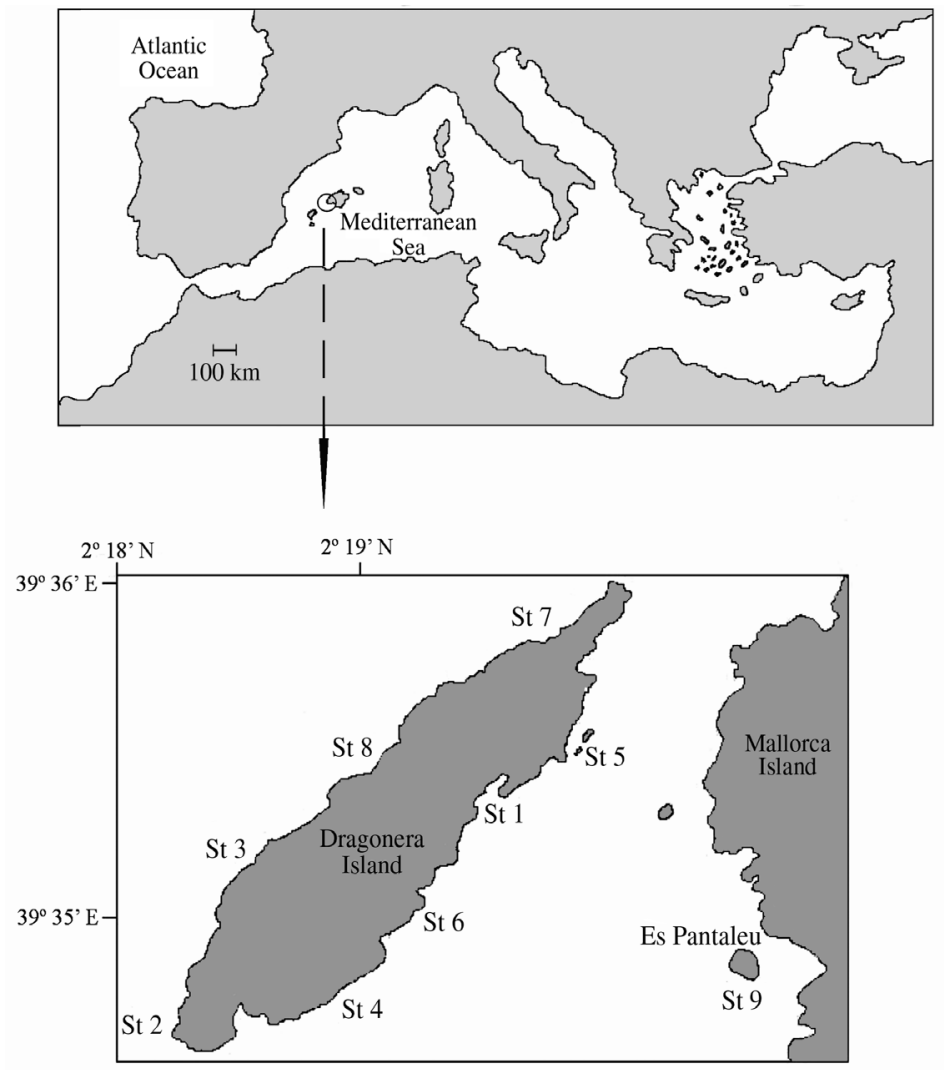

Fig. 1. Location of the study area for quantification of Percnon gibbesi densities. St.: Site 
meter of the transect so that the number of replicates (each replicate is $1 \mathrm{~m}^{2}$ ) for each transect was 200. All factors were fixed orthogonal factors. Homogeneity of variance was assessed by Cochran's $C$-test and data were analysed with the program SYSTAT 10.2.

\section{RESULTS}

\section{Demographic structure}

The length-frequency distribution of the crabs caught at the 2 sampling localities (Dragonera and Sa Ràpita) was tested with a Kruskal-Wallis test, and no differences were detected among the localities $(p=0.21)$.

The carapace length (CL) of individuals observed and caught ranged from 5 to $40 \mathrm{~mm}$ (Fig. 2). Modal distribution was 21 to $25 \mathrm{~mm} \mathrm{CL}$, with a frequency around $40 \%$. The carapace intervals $16-20 \mathrm{~mm}$ and $21-25 \mathrm{~mm}$ both presented similar frequencies (around 20\%), while individuals larger than $26 \mathrm{~mm}$ exhibited a frequency around $8 \%$. Crabs smaller than $10 \mathrm{~mm}$ presented a frequency of $10 \%$.

\section{Sex ratio and sexual dimorphism}

The sex ratio of the population was 2 males for every 3 females, favoring females $\mathrm{m}: \mathrm{f}=0.66$ (38 and 62 individuals, respectively) and $87 \%$ of females were ovigerous (Fig. 3). With respect to sexual dimorphism, the right and left cheliped propodus were equal in size but much wider and longer in males than in females for CLs larger than $30 \mathrm{~mm}$ (in $100 \%$ of the cases).

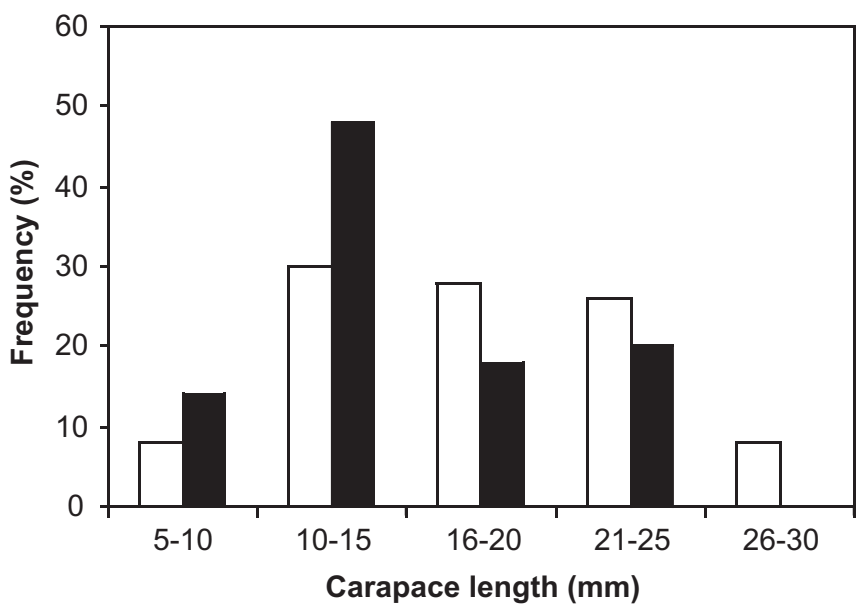

Fig. 2. Percnon gibbesi. Length-frequency distribution of crabs collected at Dragonera (black bars, $\mathrm{n}=50$ ) and collected at Sa Ràpita (white bars, $\mathrm{n}=50$ ). No $26-30 \mathrm{~mm}$ crabs collected at Dragonera

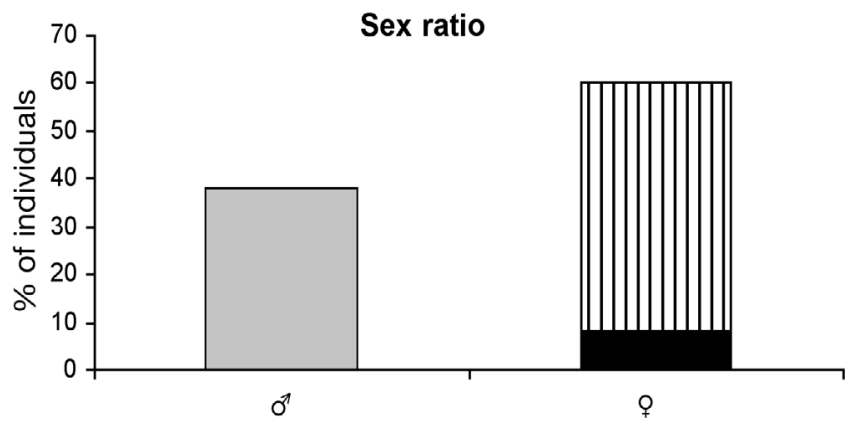

Fig. 3. Percnon gibbesi. Sex ratio of males (grey), females (black) and ovigerous females (striped)

\section{Spatial distribution}

The mean density of Percnon gibbesi at the sampling sites ranged from 0.22 to 7.66 ind. $200 \mathrm{~m}^{-2}$. P. gibbesi was present at all sampling sites, although total abundances were highly variable (Fig. 4). A total number of 69 individuals were counted at Sites 1 and 9 (boulders of variable size with algal cover not higher than $0.5 \mathrm{~cm}$ ). A total of $41 \mathrm{ind}$. site ${ }^{-1}$ were observed at Site 5 (boulders of variable size with algal cover not higher than $0.5 \mathrm{~cm}$ and communities of algal turf and algal sheets higher than $0.5 \mathrm{~cm}$ with a dominance of macroalgae), and 32 crabs at Site 8 (vertical walls) were observed. Minimum abundances were found at Sites 6 and 4 (communities of algal turf and algal sheets higher than $0.5 \mathrm{~cm}$ with a dominance of macroalgae), mean abundance at Site 6 being 0.22 ind. and at Site 40.78 ind.

Percnon gibbesi seems to have a patchy distribution, with most records corresponding to groups of individuals from 2 up to 14 in the same spot. Within a transect,

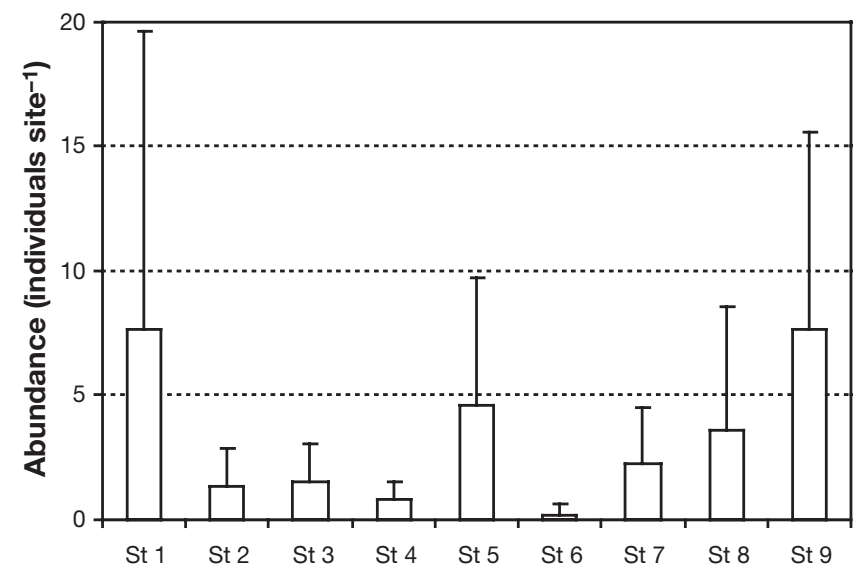

Fig. 4. Percnon gibbesi. Mean abundance at each sampling station. Bars represents mean abundances; errors bars indicate +2 SE. St: Site 
a maximum of 14 aggregations were found. Differences in abundance between transects of the same sites were high. Variation of densities among habitats was significant, showing a high affinity of $P$. gibbesi for boulders of variable size with algal cover not higher than $0.5 \mathrm{~cm}(F=32.47, \mathrm{p}<0.001,1$-way ANOVA $i=$ $0.64, \mathrm{p}=0.000001$ ).

Three-way ANOVA tested the interaction between habitat type, size of the individuals and depth (Table 1). The significance of the interaction Size $x$ Depth showed a partitioning of crab size along the depth gradient. The interactions of Habitat type $x$ Depth and Habitat type $\times$ Size were highly significant, indicating not only differences between habitats but also among depths and size of the crabs (Table 1).

\section{Bathymetric distribution}

The bathymetric distribution of Percnon gibbesi is within the range of 0 to $4 \mathrm{~m}$ depth. Most individuals ( $84 \%$ ) were found from 0 to $2 \mathrm{~m}$ depth, while no specimens were found at the supralittoral zone or deeper than $8 \mathrm{~m}$. A maximum number of individuals (19\%) was observed around $1 \mathrm{~m}$, more specifically between 0.5 and $0.75 \mathrm{~m}$ (Fig. 5). Individuals smaller than $10 \mathrm{~mm}$ CL were observed only at depths less than $1 \mathrm{~m}$, while bigger crabs were observed at depths of 3 to $4 \mathrm{~m}$.

\section{Ethology}

Percnon gibbesi was usually found under boulders, in narrow crevices, or flat rocky platforms with low algal coverage. A varied size range of crabs was observed, mainly on the vertical sides of the boulders.

Aposematic mimetic coloration patterns were also associated with crabs inhabiting flattened surfaces. Percnon gibbesi is vulnerable to predation by fishes and other invertebrates and uses an evasive behavior

Table 1. Percnon gibbesi. ANOVA on the effect of habitat type, depth and size on distribution. Hab: habitat type; CL: carapace length; $Z$ : depth

\begin{tabular}{|lcccc|}
\hline $\begin{array}{c}\text { Source of } \\
\text { variation }\end{array}$ & df & MS & F-ratio & p-level \\
\hline Hab & 2 & 0.066 & 114.157 & $<0.001$ \\
Size $($ CL) & 5 & 0.0107 & 18.546 & $<0.001$ \\
Depth $(Z)$ & 3 & 0.029 & 50.723 & $<0.001$ \\
$\mathrm{CL} \times Z$ & 15 & 0.002 & 4.090 & $<0.001$ \\
$\mathrm{Hab} \times \mathrm{CL}$ & 10 & 0.003 & 5.058 & $<0.001$ \\
$\mathrm{Hab} \times Z$ & 6 & 0.020 & 36.179 & $<0.001$ \\
Hab $\times$ CL $\times Z$ & 71 & 0.09 & 11.632 & $<0.001$ \\
Residual & 44030 & 0.001 & & \\
\hline
\end{tabular}

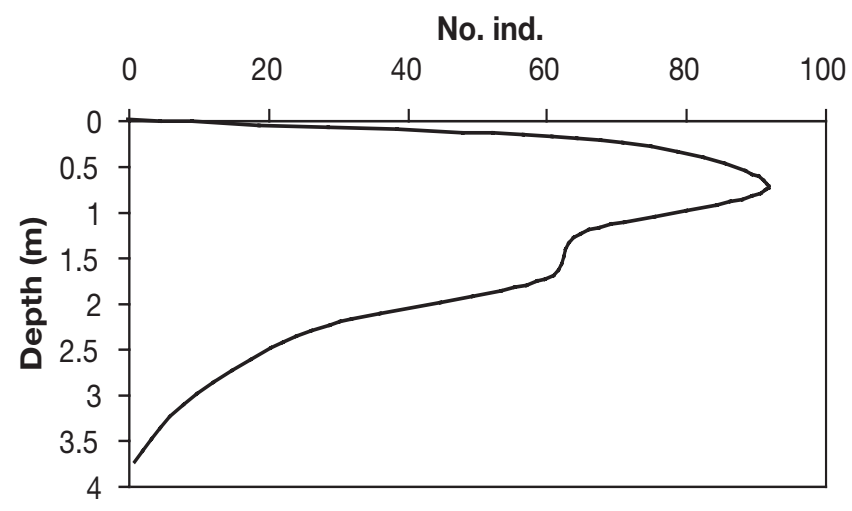

Fig. 5. Percnon gibbesi. Bathymetric distribution of crabs in Mallorcan waters

when disturbed. Specimens will run and jump, searching for refuge in the crevices when threatened. Unfortunately for them, at sunset, many individuals become vulnerable whilst feeding.

Observations of the food selection of Percnon gibbesi showed that they display an opportunistic behavior, feeding on algae (e.g. Corallina sp., Dyctiota sp.), as well as on pagurids and polychaetes (authors' pers. obs.), whichever were available. Feeding appeared to be the reason that the chelae detached food particles from the boulders.

\section{DISCUSSION}

The size distribution of an invading population may be an important determinant of its potential impact on native biota (Grosholz \& Ruiz 1996). Our study indicated that in the population of the alien Percnon gibbesi present in the waters of the Balearic Islands individuals ranging from 21 to $25 \mathrm{~mm}$ CL predominated. This size corresponded to mature ovigerous females. This observation was in accordance with Cannicci et al. (1999), who calculated the sex ratio in the range of other Grapsidae species in Mediterranean waters and also reported a predominance of females. Dominance of ovigerous females confirms the presence of breeding populations in the Balearics and along the Mediterranean coasts, as has been documented in Sicily, Ischia and Ponza (S. Deudero pers. obs.). The number of small specimens was low within the population, and this could be linked to the fact that recruitment occurs in early summer and the crabs were sampled at the end of July. These individuals occurred exclusively in the upper $1 \mathrm{~m}$, while larger specimens occupied the best spots in terms of food availability and shelter from predation. These observations may indicate the partitioning of resources between recruits/juveniles and adults, with younger crabs 
being excluded from certain habitats. Size difference is important not only in intraspecific relations but a size increase may also alter the predation-prey relationship among crabs in the introduced range (Grosholz \& Ruiz 1996), which should be tested for $P$. gibbesi in future studies.

Habitat is also a factor that seems to significantly influence the distribution of Percnon gibbesi. This species is associated with shallow rocky bottoms that have boulders where the crab can easily hide from predators. Neither macroalgae nor other macrobenthic organisms colonized any of the boulder surfaces. This habitat preference was also reported in Sicilian waters by Pipitone et al. (2001). P. gibbesi presented a patchy distribution, forming groups of 2 to 5 individuals on the rocky bottoms. The high variability in abundance of $P$. gibbesi between transects may be explained by this patchy distribution, with strong aggregation patterns linked to the high affinity of this species for boulders. The selfish herd hypothesis predicts that aggregations form because individuals move towards one another, and that this movement will minimize predation risk as measured by the domain of danger (Viscido et al. 2001, Viscido \& Wethey 2002). Several decapod species also show aggregation due to reproduction (Stone \& O'Clair 2002). In this study, these hypotheses were not tested, but both the avoidance of predation or reproduction (high number of ovigerous females) might influence aggregation. In contrast to most Grapsidae (e.g. Omori et al. 1998, Tsai et al. 2000), P. gibbesi does not show a tendency towards a semi-terrestrial lifestyle. Indeed, this species exhibited a very limited bathymetric distribution, at least during the summer season, restricted to the infralittoral zone from 0 to $4 \mathrm{~m}$ depth, with maximum abundances at $1 \mathrm{~m}$ depth. Some specimens have been observed down to $8 \mathrm{~m}$ (Valls pers. obs.). We may assume that bathymetric distribution is limited to the upper meters to avoid predation by macrocarnivorous feeders such as grouper, e.g. Epinephelus spp. or bass Serranus spp. However, further studies are needed to establish the lower depth limits of this crab.

The community impact of an alien depends on the trophic state of the community and the trophic role of the invader (Vitousek 1990). Additional impacts through trophic cascades are likely to occur if the invader significantly reduces the resources on the next trophic level down (Power 1992). Whether the introduced species brings significant changes to the lower or higher trophic level of the native fauna is an important factor to investigate (Grosholz \& Ruiz 1996). A non-native decapod species off the west coast of North America, Carcinus maenas, was observed to have a large impact on the surrounding benthic invertebrates (Grosholz \& Ruiz 1996). Pipitone et al. (2001) reported a diet of Percnon gibbesi based on small algae or other epibenthic organisms, while Schmalfuss (1976) hypothesized predation on small fish. In the present study, most individuals of $P$. gibbesi were active during the day, showing intense feeding activity on algae, especially at sunset. To estimate the grazing impact on the algal communities and the ecological impacts of $P$. gibbesi on the upper infralittoral zone, future study aimed at determining the feeding and ingestion rates of this species is encouraged. The observed distribution patterns and densities of $P$. gibbesi in Mallorcan waters may suggest a spatial resource partitioning and exclusion of other native crab species. P. gibbesi does not seem to be a potential competitor for the pebble crab Eriphia verrucosa or Pachygrapsus marmoratus. E. verrucosa occupies infralittoral crevices at shadow zones with a well-developed algal coverage (Flores \& Paula 2001). P. marmoratus inhabits supralittoral crevices (Flores \& Paula 2001). Thus, recources available to $P$. gibbesi appear to overlap spatial only with those of Eriphia verrucosa, not with Pachygrapsus spp. Other possible competitor species could be the scorpionfish Scorpaena porcus and the grouper Epinephelus marginatus, although trophic studies will be necessary to confirm these hypotheses. The data suggest that the ecological niche of $P$. gibbesi does not interfere with other benthic organisms although its habitat (and probably its feeding habits) are similar to the juveniles of Eriphia sp. The potential of $P$. gibbesi to colonize biotopes with low diversity (e.g. harbours) and high particle loads suggests further habitat separations, although further studies in control areas without $P$. gibbesi will be necessary to test this hypothesis.

The impact of an introduced species also depends, in part, upon the extent of the invasion (i.e. the density). Knowing how far and how fast the alien species will increase its range is an integral part of predicting the ultimate range of the exotic species (Roughgarden 1986). Percnon gibbesi has been observed along the southwest of Mallorca in high densities, reaching up to 3 ind. $\mathrm{m}^{-2}$. To our knowledge there are no previous studies on $P$. gibbesi densities, which would be important to determine the range of expansion. Other species that inhabit the supralittoral, mesolittoral and infralittoral zone have much lower densities, e.g. Eriphia verrucosa (0.05 ind. $\mathrm{m}^{-2}$ ) and Pachygrapsus marmoratus (0.4 ind. $\mathrm{m}^{-2}$ ) (Flores \& Paula 2001). The high densities of $P$. gibbesi recorded in our study confirm previous citations on the spread of the species throughout the Mediterranean and validate the explosive expansion of this species along western Mediterranean waters since the first record in 1999.

The present study has added new data to previous observations of Percnon gibbesi in the Mediterranean. It has also expanded the knowledge base on factors 
(e.g. habitat preference, density, population structure, distribution) which are important to determine the potential further expansion of this species and its likely impact on the native fauna. Due to the complex mechanisms of the invasion, future investigations are required. Some suggestions for further studies on the biology of this species include: (1) vigilance programs to follow its demographic evolution and determine its expansion rates, (2) studies to detect new colonization spots, (3) studies to detect a medium-term study on length structure to predict reproductive output, and (4) cross information on competitors and predators.

Acknowledgements. The authors are most grateful to $\mathrm{M}$. Valls, R. Saez, and D. de León for their help in sampling at sea, and also to M. Garcia, Victor, and T. Busquets for their valuable help in collecting samples. A special thanks to L. Riera for accommodation facilities and support. Thanks to the Servei de Ports i Litoral del Govern Balear for mooring facilities. Thanks to the Societat d'Història Natural de les Illes Balears for supporting our research. This research was funded by the Departament de Medi Ambient i Natura del Consell Insular de Mallorca and the Fundació Sa Nostra de Balears. We also thank the 3 anonymous referees for their valuable corrections.

\section{LITERATURE CITED}

Briand F (ed) (2002) CIESM atlas of exotic species in the Mediterranean, Vol 2. CIESM Publishers, Monaco

Cannicci S, Paula J, Vannini M (1999) Activity pattern and spatial strategy in Pachygrapsus marmoratus (Decapoda: Grapsidae) from Mediterranean and Atlantic shores. Mar Biol 133:429-435

Carlton JT (1989) Man's role in changing the face of the ocean: biological invasions and implications for conservation of near-shore environment. Conserv Biol 3:265-273

Carlton JT, Geller JB (1993) Ecological roulette: the global transport of non-indigenous marine organisms. Science 261:78-82

Ceccherelli G, Piazzi L, Balata D (2002) Spread of introduced Caulerpa species in macroalgal habitats. J Exp Mar Biol Ecol 280(1-2):1-11

Ehrlich PR (1989) Attributes of invaders and the invading processes: vertebrates. In: Drake JA, Mooney HA, di Castri Groves RH, Kruger FJ, Rejmanek M, Williamson M (eds) Biological invasions: a global perspective. John Wiley \& Sons, New York, p 315-328

Flores AAV, Paula J (2001) Intertidal distribution and species composition of brachyuran crabs at two rocky shores in central Portugal. Hydrobiologia 449:171-177

Galil B, Froglia C, Nöel P (2002) CIESM atlas of exotic species in the Mediterranean, Vol 2. In: Briand F (ed) Crustaceans: decapods and stomatopods. CIESM Publishers, Monaco, p 1-192

Editorial responsibility: Otto Kinne (Editor-in-Chief), Oldendorf/Luhe, Germany
Garcia L, Reviriego B (2000) Presència del cranc subtropical Percnon gibbesi (H. Milne Edwards, 1853) (Crustacea, Decapoda, Grapsidae) a les Illes Balears. Primera cita a la Mediterrània occidental. Bol Soc Hist Nat Bal 43: 81-89

Grosholz ED, Ruiz GM (1996) Predicting the impact of introduced marine species: lessons from the multiple invasions of the European green crab Carcinus maenas. Biol Conserv 78:59-66

Mori M, Vacchi M (2002) On a new occurrence of the alien flat crab, Percnon gibbesi (H. Milne Edwards), in the southern Sicily (Central Mediterranean Sea). Ann Mus Civ Stor Nat 'G. Doria' 94:295-301

Müller C (2001) Erstnachweis der Flachkrabbe Percnon gibbesi (Crustacea: Decapoda: Grapsidae) für die Balearischen Inseln. Senckenberg Marit 31:83-89

Omori K, Irawan B, Kikutani Y (1998) Studies on the salinity and desiccation tolerances of Helice tridens and Helice japonica (Decapoda: Grapsidae). Hydrobiologia 386: $27-36$

Pipitone C, Badalamenti F, Sparrow A (2001) Contribution to the knowledge of Percnon gibbesi (Decapoda, Grapsidae), an exotic species spreading rapidly in Sicilian waters. Crustaceana 74(10):1009-1017

Power ME (1992) Top-down and bottom-up forces in food webs: Do plants have primacy? Ecology 73:733-746

Relini M, Orsi L, Puccio V, Azzurro E (2000) The exotic crab Percnon gibbesi (H. Milne Edwards, 1853) (Decapoda, Grapsidae) in the central Mediterranean. Sci Mar 64: $337-340$

Roughgarden J (1986) Predicting invasion and rates of spread. In: Mooney HA, Drake JA (eds) Ecology of biological invasions of North America and Hawaii. SpringerVerlag, New York, p 179-188

Schmalfuss H (1976) Ökologisch-funktionmorphologische Untersushungen an karibischen Krabben (Decapoda Brachyura). I. Percnon gibbesi (H. Milne Edwards, 1853) (Grapsidae, Plagusiinae) Stud Neotrop Fauna Environ 11: 211-222

Simberloff D (2001) Biological invasions-How are they affecting us, and what can we do about them? West N Am Nat 61:308-315

Stone RP, O'Clair CE (2002) Behavior of female Dungeness crabs, Cancer magister, in a glacial southeast Alaska estuary: homing, brooding-site fidelity, seasonal movements, and habitat use. J Crustac Biol 22(2):481-492

Tsai ML, Li JJ, Dai CF (2000) Is large body size always advantageous for terrestrial adaptation? A study of water balance in a semi-terrestrial crab, Sesarmops intermedium (Crustacea: Grapsidae). Evol Ecol 14 (1): 61-78

Viscido SV, Wethey DS (2002) Quantitative analysis of fiddler crab flock movement: evidence for 'selfish herd' behaviour. Anim Behav 63 (4):735-741

Viscido SV, Miller M, Wethey DS (2001) The response of a selfish herd to an attack from outside the group perimeter. J Theor Biol 208 (3):315-328

Vitousek PM (1990) Biological invasions and ecosystem processes: towards an integration of population biology and ecosystem studies. Oikos 57:7-1

Submitted: April 20, 2004; Accepted: August 12, 2004

Proofs received from author: January 6, 2005 